Therefore, organizations should consider whether universal screening will produce a high enough yield to offset economic and logistical consequences.

This study had limitations related to generalizability and data analysis. It was conducted at an academic health center in Indiana, and the generalizability of these results to other settings and states with higher incidence may be limited. For example, when this study was conducted, Indiana was on the lower end of case rate per $100,000(1,611)$ compared to states with higher rates such as Louisiana $(3,431)$ and Florida $(3,114){ }^{1}$ In addition, the data analysis focus was descriptive, thus limiting conclusions about relationships and causality or the effects of this program on healthcare worker safety.

Our study validated the value of the preprocedural screening program in allowing the resumption of elective surgical procedures. It was further strengthened through procedural team adoption and sustainment. These findings may help inform decision making of like organizations attempting to enhance safety while resuming elective procedures.

Acknowledgments. The authors thank Nikki Walke, Administrative Director for Perioperative Services, for her contribution to the conception of the preprocedural screening program and support with implementation.

Financial support. No financial support was provided for this study.

Conflicts of interest. All authors report no conflicts of interest relevant to this article.

\section{References}

1. COVID data tracker. Centers for Disease Control and Prevention website. https://covid.cdc.gov/covid-data-tracker/\#cases. Published 2020. Accessed September 3, 2020.
2. COVID-19: guidance for triage of nonemergent surgical procedures American College of Surgeons website. https://www.facs.org/covid-19/ clinical-guidance/triage. Published 2020. Accessed May 20, 2020.

3. Joint statement: roadmap for resuming elective surgery after COVID-19 pandemic. American College of Surgeons website. https://www.facs.org/ covid-19/clinical-guidance/roadmap-elective-surgery. Published 2020. Accessed September 17, 2020.

4. CMS releases recommendations on adult elective surgeries, nonessential medical, surgical, and dental procedures during COVID-19 response. Centers for Medicare and Medicaid Services website. https://www.cms.gov/ newsroom/press-releases/cms-releases-recommendations-adult-electivesurgeries-non-essential-medical-surgical-and-dental. Published 2020. Accessed September 17, 2020.

5. Chapter 8: Learning from SARS: Renewal of public health in Canada-clinical and public health systems issues arising from the outbreak of SARS in Toronto. Government of Canada website. https://www.canada.ca/en/publichealth/services/reports-publications/learning-sars-renewal-public-healthcanada/chapter-8-clinical-public-health-systems-issues-arising-outbreaksars-toronto.html\#s8c4. Published 2004. Accessed January 28, 2021.

6. Schull MJ, Stukel TA, Vermeulen MJ, et al. Effect of widespread restrictions on the use of hospital services during an outbreak of severe acute respiratory syndrome. CMAJ 2007;176:1827-1832.

7. Symptoms of coronavirus (COVID-19). Centers for Disease Control and Prevention website. https://www.cdc.gov/coronavirus/2019-ncov/downloads/ COVID19-symptoms.pdf. Published 2020. Accessed January 28, 2021.

8. Panesar K, Dodson T, Lynch J, Bryson-Cahn C, Chew L, Dillon J. Evolution of COVID-19 guidelines for University of Washington oral and maxillofacial surgery patient care. J Oral Maxillofac Surg 2020;78:1136-1146.

9. COVID-19: What proportion are asymptomatic? Center for EvidenceBased Medicine University of Oxford website. https://www.cebm.net/ covid-19/covid-19-what-proportion-are-asymptomatic/. Published 2020. Accessed May 20, 2020.

10. 2019 novel coronavirus (COVID-19). Indiana state government website. https://www.coronavirus.in.gov/. Published 2020. Accessed October 15, 2020.

\title{
Mask mandates in light of DANMASK-19
}

\author{
Sajith Matthews MD \\ Division of General Medicine, Department of Internal Medicine, Wayne State University, Detroit, Michigan
}

To the Editor-When public pressure mounted for the use of hydroxychloroquine (HCQ) for prophylaxis or treatment of coronavirus disease 2019 (COVID-19), our nation's leading scientists exercised prudence and recommended awaiting the results of randomized controlled trials (RCTs) before considering its use. Such restraint proved to be invaluable because evidence from these RCTs ultimately showed that there is no benefit but rather harm with HCQ use in the treatment of COVID- 19., ${ }^{1,2}$ A similar focus on high-quality evidence has not been taken for masks and effect on mitigating the spread of disease. Internationally, public health

Author for correspondence: Sajith Matthews, E-mail: smatthew@med.wayne.edu Cite this article: Matthews S. (2022). Mask mandates in light of DANMASK-19. Infection Control \& Hospital Epidemiology, 43: 548-549, https://doi.org/10.1017/ ice. 2021.35 mandates for masks in the community, has varied from no masks to mandatory masks when outside in crowds to wearing masks when symptomatic. ${ }^{3-5}$ Acknowledging the lack of evidence from RCTs of masks having any additive effects on mitigating the transmission of severe acute respiratory syndrome coronavirus 2 (SARS-CoV-2), ${ }^{5}$ public mask use was recommended by the Center for Disease Control (CDC) for protective effect (among healthy individuals) and not just source control (among symptomatic individuals).

The DANMASK-19 was a well-powered randomized controlled trial (6,000 participants) with $46 \%$ proper and $47 \%$ predominantly proper adherence to mask use in a setting of uncommon mask use, moderate spread of infection, and reasonable adherence to social distancing and handwashing. ${ }^{6}$ The DANMASK-19 trial was consistent with the 12 previous $\mathrm{RCTs}^{7}$ which showed, with

( ) The Author(s), 2021. Published by Cambridge University Press on behalf of The Society for Healthcare Epidemiology of America. This is an Open Access article, distributed under the terms of the Creative Commons Attribution licence (http://creativecommons.org/licenses/by/4.0/), which permits unrestricted re-use, distribution, and reproduction in any medium, provided the original work is properly cited. 
moderate certainty evidence, that there were negligible additive effects from masks in the prevention of respiratory infections. The DANMASK-19 trial showed the mask's protective effect to be inconclusive and difference between the 2 groups to not be statistically significant in the community setting. Despite the evidence from previous RCTs on influenza and other respiratory viral infections, there was suspicion from observational studies ${ }^{8}$ that severe acute respiratory syndrome SARS-CoV-2 behaved differently and that droplet transmission could be mitigated by mask use in the presymptomatic phase..$^{5}$ Therefore, the implementation of universal mask use was justified while awaiting the results DANMASK 19. In light of the inconclusive evidence from DANMASK 19 and the previous RCTs, the case for a protective effect from COVID 19 lacks evidence and requires modification from public health officials.

Although this study did not assess source control, the effect of masks is compelling, when restricted to contacts of index cases receiving the intervention within 36 hours of symptom onset. ${ }^{9}$ Hence, mask use among symptomatic individuals and their contacts is evidence based. On the contrary, long-term effects of mask use among healthy individuals is unknown, ${ }^{3}$ and short-term effects include breathing difficulties, self infection through touching eyes due to irritation from exhaled air from masks, and a false sense of security from mask while neglecting social distancing. ${ }^{10}$ The argument for masks having a variolation effect in COVID-19 is compelling, ${ }^{11}$ but it lacks the support of evidence from cohort studies. Hence, with the current data available, the best case for masks appears to be in symptomatic patients and recommended (not mandatory) use in crowded settings. Wisdom to use measured language in what we "mandate" and "recommend" would be advised. We must decide with prudence, as we did with HCQ, what we choose to be "absolutely essential" measures, and we must decide these based upon robust evidence. In the haste of establishing "life saving" measures, we may be instead be losing the public's trust by not having the supportive evidence and unintentionally placing the lives of the community and healthcare workers at risk.

Acknowledgments. The author's affiliation center belongs to the Integrative Biosciences Center, Wayne State University, Detroit, Michigan. The funders had no role in the decision to publish or preparation of the manuscript.
Financial support. No financial support was provided relevant to this article.

Conflicts of interest. The author reports no conflicts of interest relevant to this article.

\section{References}

1. Boulware DR, Pullen MF, Bangdiwala AS, et al. A randomized trial of hydroxychloroquine as postexposure prophylaxis for COVID-19. $N$ Engl J Med 2020;383:517-525.

2. RECOVERY Collaborative Group, Horby P, Mafham M, Linsell L, Bell JL. Effect of hydroxychloroquine in hospitalized patients with COVID-19. N Engl J Med 2020;383:2030-2040.

3. Javid B, Weekes MP, Matheson NJ. COVID-19: should the public wear face masks? BMJ 2020;369:m1442.

4. Bundgaard H, Bundgaard JS, Raaschou-Pedersen DET, et al. Face masks for the prevention of COVID-19-rationale and design of the randomised controlled trial DANMASK-19. Dan Med J 2020;67:A05200363.

5. Advice on the use of masks in the context of COVID-19: interim guidance. World Health Organization website. https:/www.who.int/publications/i/ item/advice-on-the-use-of-masks-in-the-community-during-home-careand-in-healthcare-settings-in-the-context-of-the-novel-coronavirus-(2019ncov)-outbreak. Published June 5, 2020. Accessed January 26, 2021.

6. Bundgaard H, Bundgaard JS, Raaschou-Pedersen DET, et al. Effectiveness of adding a mask recommendation to other public health measures to prevent SARS-CoV-2 infection in Danish mask wearers: a randomized controlled trial. Ann Intern Med 2020:M20-6817.

7. Chou R, Dana T, Jungbauer R, et al. Masks for prevention of respiratory virus infections, including SARS-CoV-2, in health care and community settings: a living rapid review. Ann Intern Med 2020;173: 542-555.

8. Chu DK, Akl EA, Duda S, et al. Physical distancing, face masks, and eye protection to prevent person-to-person transmission of SARS-CoV-2 and COVID-19: a systematic review and meta-analysis. Lancet 2020;395: 1973-1987.

9. Cowling BJ, Chan KH, Fang VJ, et al. Facemasks and hand hygiene to prevent influenza transmission in households: a cluster randomized trial. Ann Intern Med 2009;151:437-446.

10. Lazzarino AI, Steptoe A, Hamer M, et al. COVID-19: important potential side effects of wearing face masks that we should bear in mind. BMJ 2020; 369:m2003.

11. Gandhi M, Rutherford GW. Facial masking for COVID-19-potential for "variolation" as we await a vaccine. N Engl J Med 2020;383(18):e101.

\title{
Death, masked angels: Die to save someone
}

\author{
Mohammadreza Firouzkouhi PhD (1) and Abdolghani Abdollahimohammad PhD (1) \\ Departments of Medical Surgical, Faculty of Nursing and Midwifery, Zabol University of Medical Sciences, Zabol, Iran
}

"As soon as someone is born, they say, 'He will not be saved from death. For all beings in this world, there is no salvation from death.' " Augustin, 2002

To the Editor - Death usually occurs in old age or after a severe illness, but there is no guarantee regarding when it happens. Death is part of the process of human life. But some human beings

Author for correspondence: Abdolghani Abdollahimohammad, E-mail: abdalqani@ gmail.com

Cite this article: Firouzkouhi M and Abdollahimohammad A. (2022). Death, masked angels: Die to save someone. Infection Control \& Hospital Epidemiology, 43: 549-550, https://doi.org/10.1017/ice.2021.27 consciously risk death to save others regardless of their age and family circumstances, for example, the nurses at the frontline of caring for patients in normal and abnormal situations such as war, epidemics, and crises. In the only pandemic of the 21 st century, nurses are heralded as heroes on the front pages of websites and other media with the phrases such as "battling on the frontline" and "dying in service." Broadcasted images show nurses involved in the coronavirus disease 2019 (COVID-19) pandemic with protective clothing and tired faces behind ever-present masks. The COVID-19 pandemic has meshed politics, economics, health policy, public health, and nurses around the world. The 